\title{
UCPL- 13962
}

- Final techitcal repost

INTRAYURAL ORDER NO. 2373109

T0

\section{MASTER}

LAIIRENCE LIVERYORE LAPORATORY

FOR

DEVELOPIENT OF UTGH CURRENT LOW EHERGY $\mathrm{H}^{+}$ION SOURCE

Princlpal Investigator: A.T. Forrester

Co-principal Investigator: J.T. Crow

Prepazad by A.T. Forrester, J.T. Crot, and D.M. Goebel Total Funding $\$ 14,748,00$

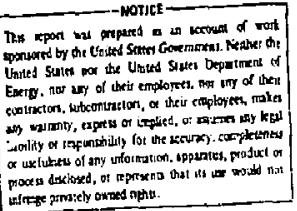




\section{Developsent of High Current Los Enercy $\mathrm{II}^{+}$Ion Source}

A. T. Forrester, Janes T. Crow, Dan M. Goebe1

\section{Introduction: The Problew}

The ultimate goal of this work is the developitent of an fon source suttable for double charge exchange of $\mathrm{D}^{+}$lons to $\mathrm{D}^{-}$lons in cesiut or ocher vapor. Since the fraction of the $D^{+}$which changes to $D^{-}$may be as high as 0.35 in the energy below one keV, the process appears very favorable. ${ }^{1}$

What is desired is a source of several hundred $\mathrm{cm}^{2}$ area, with a $\mathrm{D}^{+}$ current dessicy greater thar, say $0.2 \mathrm{~A} / \mathrm{cm}^{2}$. Small angular spread is essential with up to about 0.1 radian being acceptable.

\section{Approach}

A simple approach to this problem appears to be th ough the fine nesh extraction electrodes developed at this laboratory. ${ }^{2-4}$ In this system a single grid facing the fon source plasma constitutes the entire extraction electrode system, as shown in Fig. 1. If the potential difference between the grid and the source plasma is large compared to the lon energy at the plasina boundary, then the distance $s_{a}$ is just the Child-Langmuir distance corzasponding to the ion current density $J$ and the potential difference $V_{0}$ between the plasma and the grid.

Although we have run with negativa grid potentials, the extraction grid 1s nordally held at the same potentlal as the ion beam surroundings. In this case the Ion bean will rise to a sufficiently positive potential to trap space charge neutralizing electrons. This is lllustrated at the Jotton of Fig. 1 .

Space charge spreading at the bean edges in the accel gap can be corrected by Pierce electrodes but this is an unecessary refinement if $s_{0}$ is quch less than the lateral beam dimensions. Eurthermore, the trajectorles at the beam 
Deqvelopment of High Current Low Energy

$\mathrm{H}^{+}$Ion Source (2)

\section{Approach (continued)}

boundaries are miuch more influenced by the shape of the plasma boundary than by space charge. If $s_{0}$ is increased over the value shown in Fir. 1 , the plaswa boundary w11l be concave at the place where the boundary approaches the defining aperture, and the bean edges converge. If $s_{o}$ is decreased the plasma bulges out toward the grid and the beam elgas diverge.

There are limitations in the application of the fine mesh grld system to high current density beams. Let us consider these one at a tide.

\section{Planarity of Equiporentials}

For a grid which is too coarse, a condition such as that shown in Fiz. 2 might obtaia. In this case the potential between grid wires is significantly positive with respect to the grid wires and the plasna surface has ripples reflecting the periodicity of the grid. This phenomenon causes, as illustrated, ion interception wuch larger than the geometric cross-section of the grid wires and a large angular spread in the energing beam. 1

It is necessary to avoid this phenomenon by using grtis whose wire to wire spacing is small compared to the spacing $s_{0}$ to the plasma. In this case the ripple in potential in the plane of the grid can be expected to be a small fraction of the grdd to the plasma voltage. For square gaid of spacing "a" In each direction the rtpple in potential can be expected to fall off as $\exp -(2 \sqrt{\pi} / a)$, where $x$ is distance from the grid. For $x / a=2$ this Eactor is $1.91 \times 10^{-8}$. It is likely that a grid spacing which is $1 / 2$ the acceleration sheath thickness is ample to avoia the undesirable effects illustrated in Fig. 2. It is easy to show that under this condition space charge effects in the 
Development of High Current Low Energy

$\mathrm{H}^{+}$Ion Source

(3)

\section{Planarity of Equipotentials (continued)}

vicinity of the grids whtch would increase the ripple in voltage in the grid plane are nezligible. This can be done approxinately as follows: The space charge density at the grid is given by

$$
p=\frac{4 \varepsilon_{0}}{g} \frac{V_{0}}{s_{0}^{2}}
$$

The potential variation fron center to periphery of a cylinder of diameter of a containing that amount of charge is seen to be

$$
\Delta v=\frac{v_{0}}{36} \frac{a^{2}}{s_{0}^{2}}
$$

For $s_{0}=2 a$ this gives

$$
\Delta V=\frac{V_{0}}{144}
$$

small enough to guarantee a negligible space charge effect.

The value of $s_{0}$ can be expected to be much larger than $2 a$. For example for a 250 in. $^{-1}$ mesh, which is a commercially available tungsten grid, $a=0.004 \mathrm{ln} .=0.01 \mathrm{~cm}$. A value of $s_{0}=2 a$ would correspond to current of $0.77 \mathrm{~A} / \mathrm{cm}^{2}$ at 400 volts, far in excess of desired currents.

The assumption that the plasma boundary is planar and ion trajectories initially all parallel appears to be one that is reasonable.

IV. Grid Heating

With s/a sufficiently large, the trajectories can be expected to be essentially straighe, with small deflections produced close to the grid plane, 
Dẹvelopment of High Current Low Energy

$\mathrm{H}^{*}$ Ion Source

IV. Grid Heating (continued)

as discussed later. In this case the porver per unit area striking the grids

1s just the average power per unit area,

$$
P=J V_{0},
$$

For a circular grid wire the radiating area per unit length of wire is $\pi d$, thereas the cross-section per unit length for ion beam interception is just d. The wire temperature will be deternined by

$$
e \sigma T^{4}=P / \pi \text {, }
$$

where $e$ is the emissivity, $\sigma$ the stefan-Boltzmann constant and $T$ the absolute temperature of the wire. Vsing tungsten enissivicy values of Roessen and Hensel ${ }^{5}$, we obtain the curve shown in Fig. 3.

- UItimately the temperature limitation will be provided either by the thermonic electron emission from the grid or by the rate of evaporation of tungsten. Since thie saturation electron current becomes ${ }^{5} 0.1 \mathrm{~A} / \mathrm{cm}^{2}$ at about $2380^{n} \mathrm{~K}$ this would appear to be an upper limit to the allowable grid temperature, depending somewhat on the grid to plasma potential difference. This rould correspond to 170 watts $/ \mathrm{cm}^{2}$ of ion beam. At $2380^{\circ} \mathrm{K}$ the evaporation rate of tungsten, calculated from vapor pressure date, is $1.8 \times 10^{-11} \mathrm{~cm} / \mathrm{sec}$. At this rate it vould take about $4-1 / 2$ years to evaporate 0.001 " of tungsten. A limit of 170 watts $/ \mathrm{cm}^{2}$ would seen to be a reasonable limit.

\section{Sputtering Limit}

For heavy lons, the rate at which the grid sputters severely lirats operating time. For $\mathrm{H}^{+}$or $\mathrm{D}^{+}$this limitation is not severe. Since we are uitimately interested in $\mathrm{D}^{+}$beams let us exanine the sputtering linitation 
Dęvelopnent of High Current Low Energy

$\mathrm{H}^{+}$Ion Source (5)

\section{v. Sputcering Lidit (continued)}

in the low energy range. The sputtering yield ${ }^{7}$ for $D^{+}$on tungsten is givell by $a=7.2 \times 10^{-4}$ atoms $/ \mathrm{cm}$ at $1 \mathrm{keV}$ and dropping rapidily as the enerzy is decreased.

It is a simple matter to shos that the rate of sputtering, in $\mathrm{cm} / \mathrm{sec}$, is given by

$$
S=9.9 \times 10^{-5} \& \mathrm{~J}
$$

where $\mathrm{J}$ is the current density in $\mathrm{A} / \mathrm{cm}^{2}$. For example, if $\mathrm{J}=0.2 \mathrm{~A} / \mathrm{cm}^{2}$ and $a$ at the value given for $1 \mathrm{keV}$ we obtain

$$
\begin{aligned}
S & =1.43 \times 10^{-8} \mathrm{cg} / \mathrm{sec} \\
. & =1.24 \times 10^{-3} \mathrm{~cm} / \text { day }
\end{aligned}
$$

For a grid thickness of $2.5 \times 10^{-3}$ en this could be a serious limit. The sputtering isn't vell known below I keV but is is dropping off very rapidly in this region. For an $a=10^{-4}$ atoms/ion anticipated at $300-400$ volis the sputtering limitation on lifetime would be satisfactory.

\section{Angular Divergence}

An approximation to the divergence caused by fields near the grid can be obtained by considering each hole as acting independently and using the formula ${ }^{8}$

$$
f=4 \frac{v_{0}}{v_{2}^{\prime}-\nabla_{1}^{\prime}}
$$

for the focal length of an aperture. Take $\nabla_{2}^{\prime}$, the potential gradient on the downstrean side of the grid to be negligible compared to the gradient $4 \mathrm{~V}_{0} / \mathrm{s}_{0}$ on the upstream side. We then obtain

$$
f=3 s_{0}
$$


Development of High Current Low Energy

$H^{+}$Ion Source

\section{Angular Dlvergence (continued)}

As illustrated in Fig. 4 this yields an argular divergence

$$
\theta= \pm a / 6 s_{0} .
$$

The angular spread given by this equation, together with the ChildLangmul. equation relating $s_{0}$ to $\mathrm{J}$ and $\mathrm{V}_{0}$, and the material of the prevtous section relating the tenperature to bean posser density $\mathrm{JV}$, has been put together in the curves of Fig. 4 for a 250 in $^{-1}$ grid. For example, suppose one could say that a grid renning at $2300^{\circ} \mathrm{K}$. and angular divergence of $4^{\circ}$. from the mean path, were acceptable parameters. Fig. 4 shows that this could be obtained with a current density of $420 \mathrm{~mA} / \mathrm{cm}^{2}$ at a voltage of 350 volts. VII. Initial Tests

The concept of fine mesh extraction of low energy high density ion beams vas tested using two multipole contalnment ion sources.

Prelininary development of the fine mesh single grid system was dona with the ion source descrtbed in reference 4 . This ion source, approxinately $14 \times 14 \times 18 \mathrm{~cm}$ in s1ze, uses ceramic magnets and is capable of producing a quiet, highly uniform plasma in hydrogen (or other gases) of density approximately $\mathrm{n}=2 \times 10^{11} \mathrm{cr}^{-3}$.

A woven tungsten grid of 0.03 mm wire of 55 lines/cn mesh was used for ion acceleration. The mesh was kept tightly stretclied by stainless steel spring fingers. This assembiy is show schematically in Fig. 5. Using this assembly, a $2 \mathrm{~cm} \times 2 \mathrm{~cm}$ hydrogen ion beam of $20 \mathrm{dV} / \mathrm{cD}^{2}$ was accelerated to energies ranging from $1 \mathrm{keV}$ to $3 \mathrm{keV}$. Ylaxirum power dissipation of the grid was $60 \mathrm{~W} / \mathrm{cm}^{2}$. At this power level the grid vas a bright orange color. 
Dẹvelopment of High Current Low Energy

$\mathrm{H}^{+}$Ion Source (7)

\section{Initial Test (continued)}

The bean was collected at a target approximately $20 \mathrm{~cm}$ from the accel grid plane. Measurements of the angular divergence of the beam due to grid optics had been previously made ${ }^{5}$ using a lower current argon ion beam and were found to correspond closely to values calculated usinf eq. 9. The $20 \mathrm{~mA} / \mathrm{cm}^{2}$ hydrogen beam was clearly visible, and appeared to be untform and to have an angular divergence of less than two degrees. Examination of the grid after operation indicated no damage or distortion due to heating.

These preliminary tests indicated the feasibility of the fine mesh system for relatively high current density fon beams, but ion source linitations precluded extraction of current densities in excess of approximately $25 \mathrm{~mA} / \mathrm{cm}^{2}$. An acceierator systen was then designed and constructed for the IBIS source. 9

\section{IIigh Power Dissipation Grid Tests}

A. Experinental Assembly

The grid assembly used for high power dissipation testing of the woven tungsten grids is show schematically in Fig. 6. The boron nitride aperture limited ion extraction to a circular beam of area $2 \mathrm{~cm}^{2}$. The grid is woven tungsten, 71 lines/cn of 0.02 man wire, held in tenston by four $0.25 \mathrm{~mm}$ shick molybdenum sheets.

The ion source used (IBIS, ref. (9)) is capable of producing highly uniform quiescent plasmas with densities of a few times $10^{12} \mathrm{~cm}^{-3}$, and so is able to supply more than enough current for testing of the fine mesh grids. The experimental artangement is shown schematically in Fig. 7. The 
Develepment of High Current Low Energy

$\mathrm{H}^{+}$Ion Source (8)

\section{High Fower Diss.ipation Grid Tests}

A. Experimental Assembly (continued)

aperture plate has an area exposed to the source plasina of $240 \mathrm{~cm}^{2}$, so that monitoring the fon current to this plate provides a neasuris of the ion current density actually arrfving at the plane of the accel grid. This was taken as the primary measure of incident beat current dessity for calculations of grid power dissipation.

At high power densities, the grid emits an electron current approachiag $100 \mathrm{~mA} / \mathrm{cm}^{2}$, most of which falls into the fon source, although some of these electrons may contribute to space change neutralization of the ion bea.a. This emission current appears as a current in the accel supply, added to the ion current: extracted from the ion source. The grid 1s $73 \%$ transparent.

The ion beam propagates approxicately $15 \mathrm{~cm}$ and is collected on a vater cooled copper target. In operation the hydrogen chamber pressure is $2 \times 10^{-3}$ torr to $5 \times 10^{-3}$ torr, and so the charge exchange mean free path at $1 \mathrm{keV}$ ion energy is comparable to the beam propagation distance, so that approximately $1 / 2$ the beam can be expected to strike the collector. The target is large, and many of the slow charge exchange ions will be collected by the target. The rest fall to the surrounding screen.

B. Measurements

This accel system has been operated at beam energles between lkeV and $2 \mathrm{keV}$ and extracted current densities from 70 to $140 \mathrm{~mA} / \mathrm{cm}^{2}$. The maxinum power dissipation of the grid in this serfes of tests was $160 \mathrm{H} / \mathrm{cm}^{2}$.

The power dissipation of $160 \mathrm{w} / \mathrm{cm}^{2}$ sas calculated from an accelerator voltage of 2000 volts and an incident current density of $80 \mathrm{~mA} / \mathrm{cm}^{2}$, measured 
Dequlopment of Righ Current Lor Energy

$\mathrm{u}^{\dagger}$ Ion Source (9)

VIII. High Pover Dissipation Grid Tests

B. Keasurements (continued)

at the aperture plate. Currett in the accel high voltage supply was 200in, so that 40 ma must be attributed to electron emission from the grid or spurious . discharge or leakage. The cotal beam current after accelerarion was then $0.73 \times 2 \times 80 n t=116 n A$. The current collected at the bean target was 9Bus, IndicatIng that most of the charge exchange ions are being collected by the large target. The beam was highly visible, and appeared to have less than $5^{\circ}$ divergence.

The beam current density was increased to $110 \mathrm{~mA} / \mathrm{cm}^{2}\left(150 \mathrm{~mA} / \mathrm{cm}^{2}\right.$ incident on the accel grid) at an accel voltage of $1 \mathrm{kV}$ to obsecve the effect of increased beam density on propagation. The increased source plasma density necessary for increased ion current required an increase in the chamber neutral gas pressure, anò a corresponding increase in bean losses to charge exchange. The first eight centineters appeared to have an angular divergance of less than $5^{\circ}$. Past $8 \mathrm{~cm}$, the beam rapidiy became diffuse.

The attached pizotograph is of a beam of $50 \mathrm{~mA} / \mathrm{cm}^{2}$ at $1 \mathrm{keV}$. The bright oval near the accel end of the bean is a reflection of the accel grit in one of the flat molybdenum grid tensioners. The beam can be seen to propagate sith very low divergance. 


\section{Conclusions}

These sma1l scale tests have demonstrated the ability of the fine resh tungsten accelerator grid systen to produce lov energy hydrogen ion beans of high current density. The current densities ceasured are within a factor of two of those required for a practical double charge exchange system. The $2 \mathrm{em}^{2}$ test beam area, while much swaller than that of an operating system, is large enough to demonstrate the magnitude of ifuportant space charge effects, and beam propagation over many centimeters was accomplished with divergences comparable to those expected from accel optics calculations.

The measurements indicate that the power dissipation capability of the woven mesh grid will probably not be a limiting factor. The $160 \mathrm{w} / \mathrm{cm}^{2}$ achieved is not an ultimate limit, and would correspond to $320 \pi \mathrm{s} / \mathrm{ce}^{2}$ at . $500 \mathrm{eV}$ beam energy. Overall, the test results were very encouraging and indicate that a test of a full scale fine wesh accelerator would have a high probability oi success.

NOTICE

"Work performed under the auspices of the U.S. Department of Energy by the Lawrence Livermore Laboratory under contract number $W$ 7405-ENG $48 . "$

"This report was prepared as an account 6 . work sponsored by the United States Government. Neither the Uniled States nor the United States Department of Energy, nor any of their em. ployeces, nor any of their coniractors, subconiraclors, or their employees, makes any warranty, express or implied, or assumes any legal liability or eesponsibility for the accuracy, completeness or usefulness of any information, apparatus, product or process disclosed, or represents that its ust would not infringe privately-owned rights."

Reference to a company or product name does not imply approval or recommendation of the product by the University of California or the U.S. Department of Entrgy to the exclusion of others that may be suitable. 
1. A.S. Schlachter, Proc. of the Synap, on the Production and lieutralization of Negative Hydrogen Ions and Beass, BAL-50727 (Erookhaven, 1977) Pg. 11.

2. A.T. Forrester, J.T. Crow, N.A. Massie and D.M. Goebel, "A Multipols: Containment - Single Grid Exiraction Ion Source," UCLA Plasma Phy'sics Group Report PPG-224, June 1975.

3. A.T. Forrester, J.T. Crow and D.H. Goebel, "A Low-Energy High-Perveance, Quiescent Ion Source" Low-Energy Ion Beams, 1977.

4. J.T. Crow, A.T. Forrester, D.M. Goebel, "High Perfonance, Low Energy Ion Source" IEEE Trans. on Plasaa Science, to be published.

5. CRC Hand'book of Chemistry and Physics, 47th edition 1966-1967, p E-157.

6. RCA Beview, June 1957.

7. ORRL-5207, Atomic Data for Controlled Fusion Research, Feb. 1977.

8. J.R. Pierce "Theorized Design of Electron 3eams," Chap. 7.

9. A.T. Forrester, D.M. Goebel and J.T. Crow, "IBIS: A Hollow-Cathode Multipole Boundary Ion Source," Appl. Phys. Lett 33 11, 1978. 


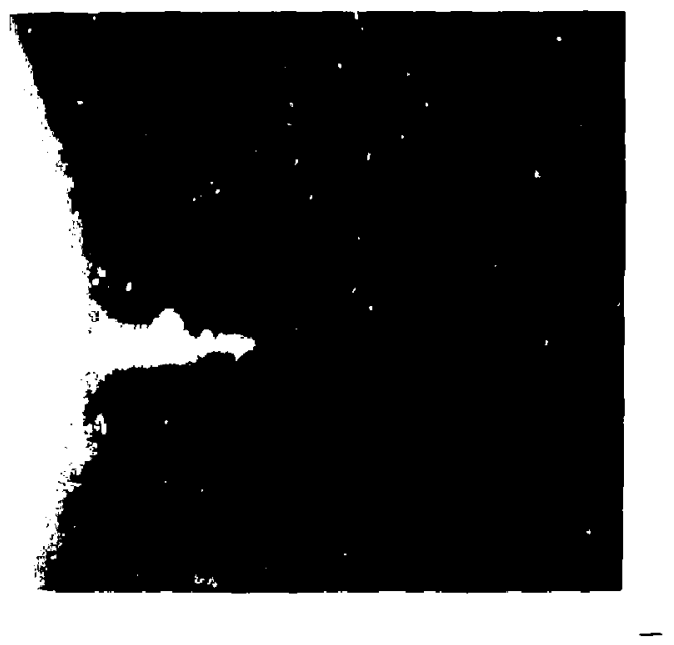

Hydrogen ion beam, $1 \mathrm{kcl}$ energy, $60 \mathrm{mM} / \mathrm{cm}^{2}$. 


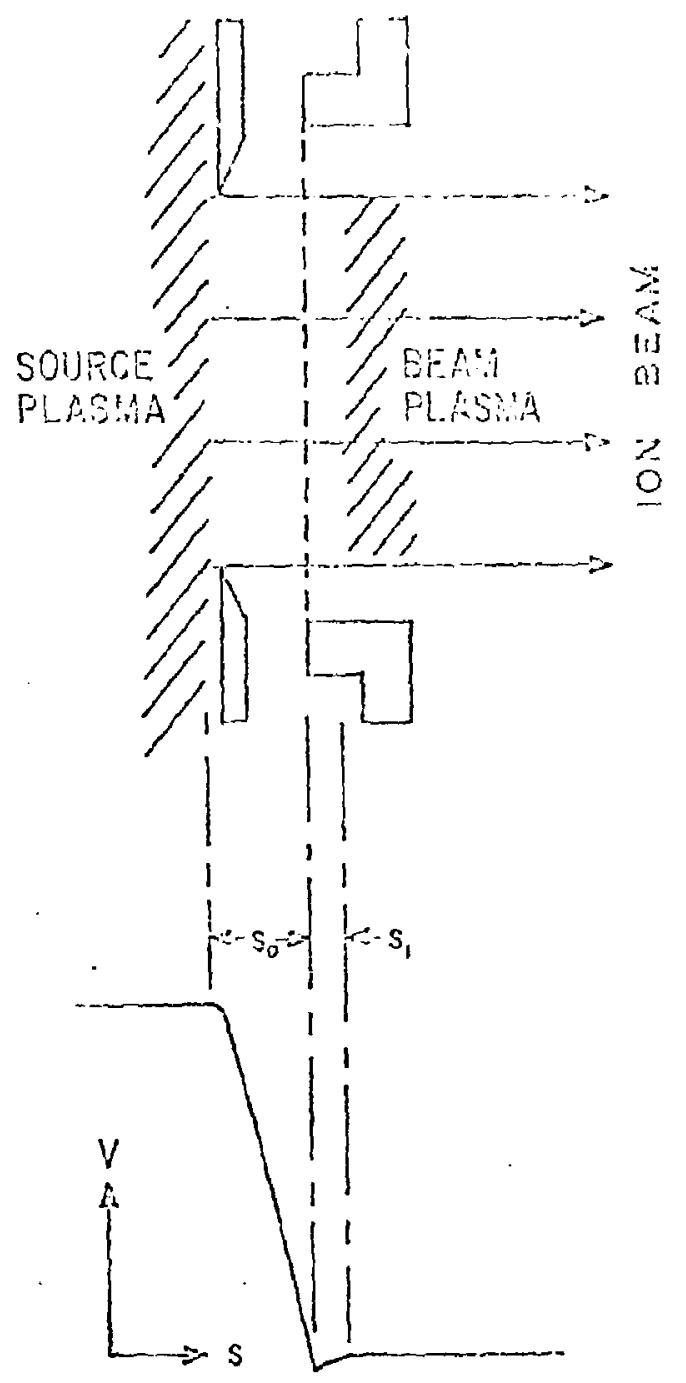

Figure 1

Sciematic of single gril extraction systen, with potential variation. 


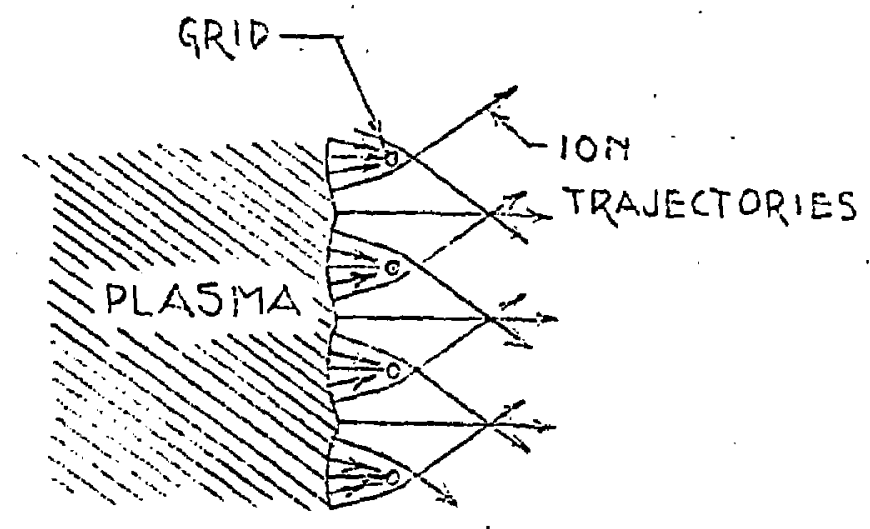

Figure 2

Difficulties associated with inadequate sheath to grid spacing ratio. 


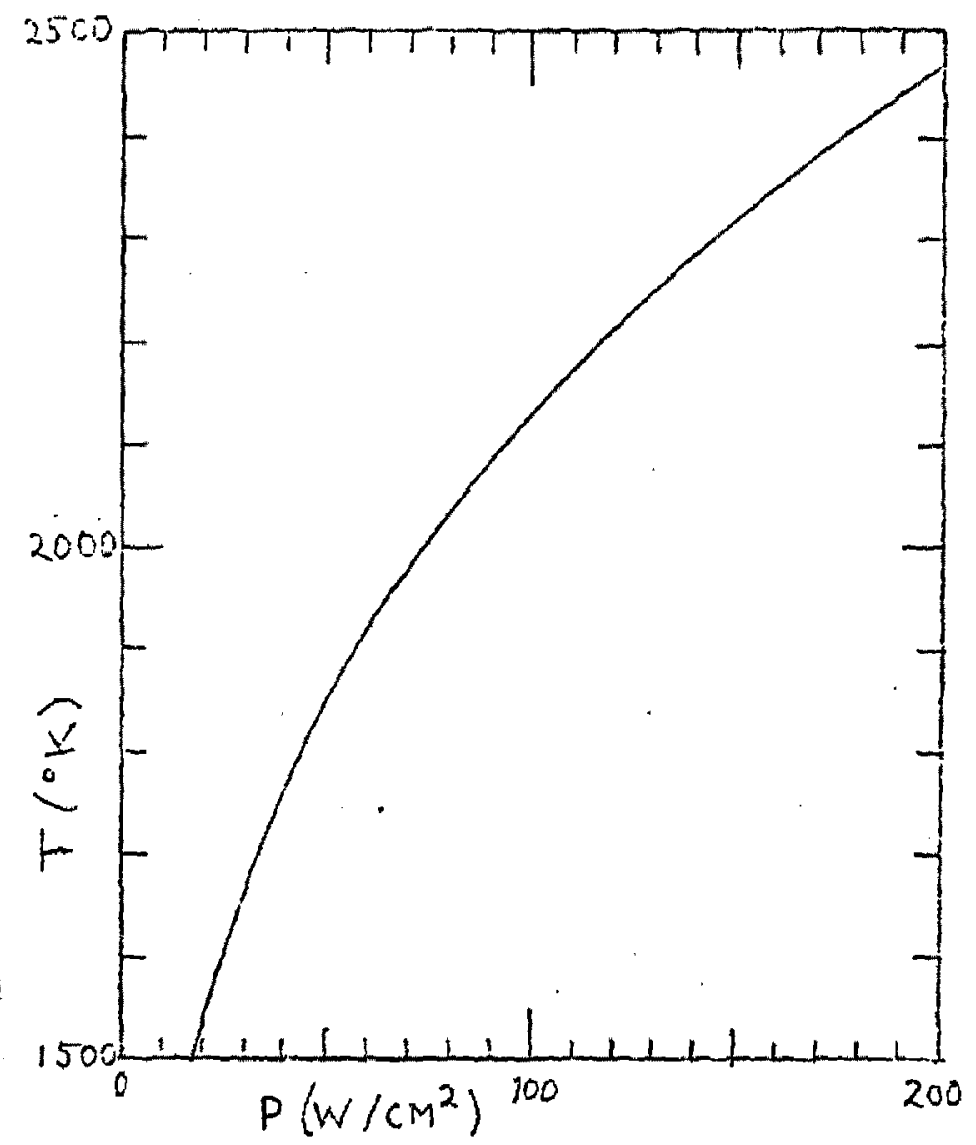

Figure 3

Theoretical temperature of a tungsten grid bombarded by an ion bean of power per unit area $P$. 


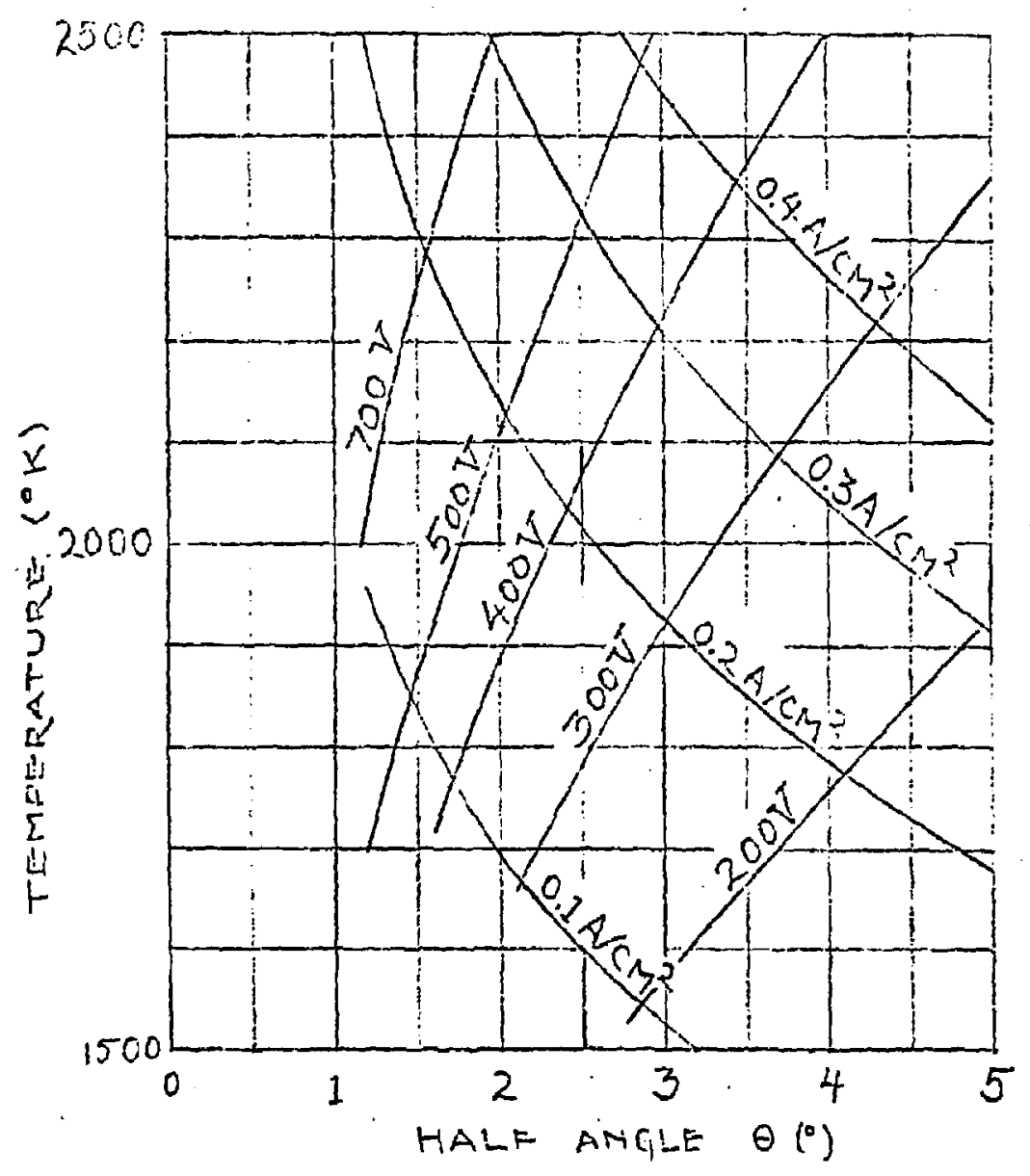

Figure 4

Current density and voltage contours for a $0^{+}$ion beam on a tenperature, divergence angle plane, for 250 line per incb tungsten mesh. 


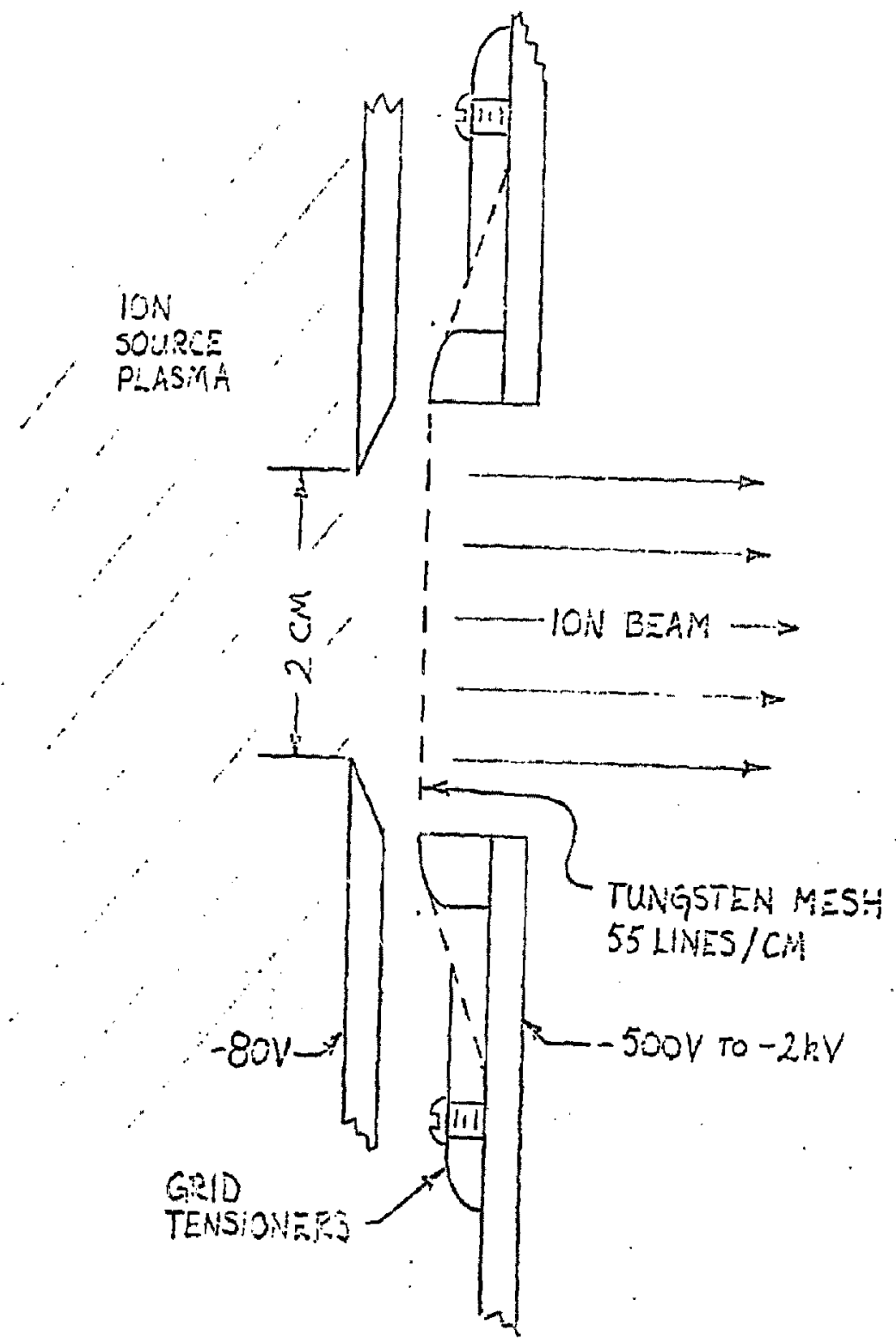

FINE MESH EXTRATOR

FIS 5 


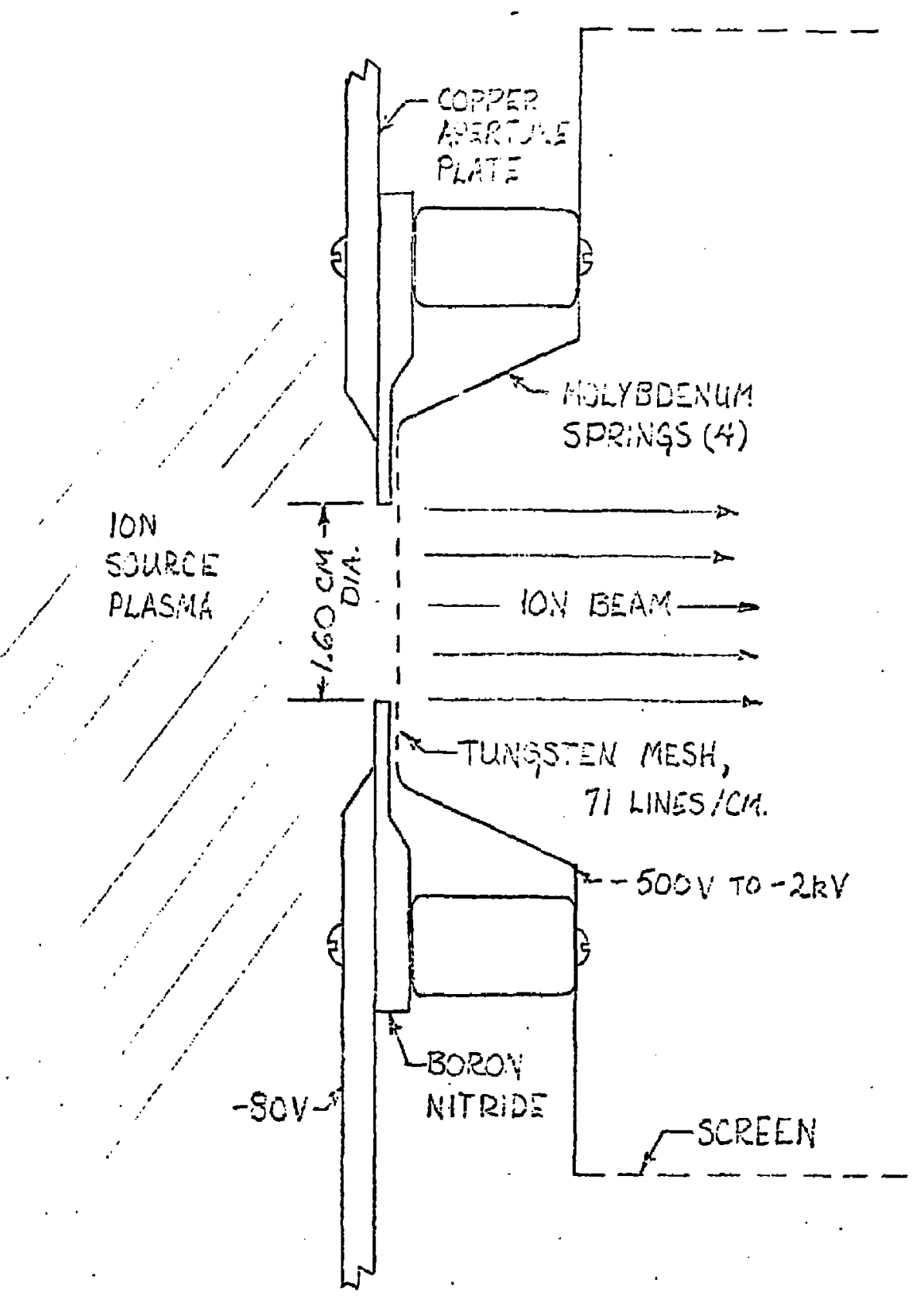

FINE MEST EXTRACTOR FO IBIS

Fig 6 


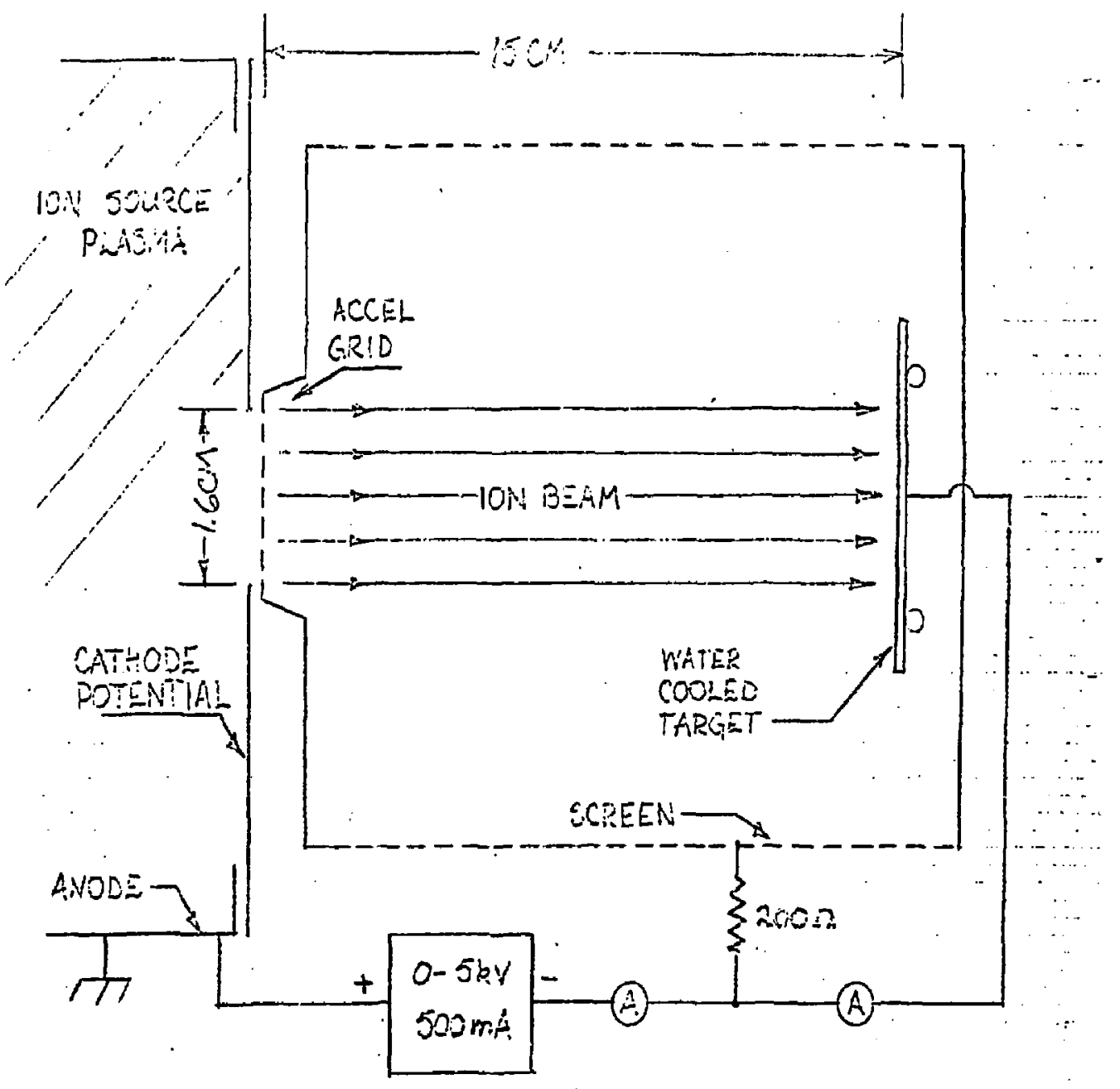

LOW ENERGY DN EEAY EXPERIMENT

Fig 7 